\title{
Suicide after bereavement: an overlooked problem
}

\author{
V. Ajdacic-Gross ${ }^{1,2 *}$, M. Ring ${ }^{1}$, E. Gadola ${ }^{1}$, C. Lauber ${ }^{1}$, M. Bopp ${ }^{2}$, F. Gutzwiller ${ }^{2}$ and W. Rössler ${ }^{1}$ \\ ${ }^{1}$ Research Unit for Clinical and Social Psychiatry, Psychiatric University Hospital, Zurich, Switzerland \\ ${ }^{2}$ Institute of Social and Preventive Medicine, University of Zurich, Zurich, Switzerland
}

Background. To examine the effect of time on suicide after bereavement among widowed persons.

Method. The data were extracted from Swiss mortality statistics for the period 1987-2005. The time between bereavement and subsequent death, specifically by suicide, was determined by linkage of individual records of married persons. The suicide rates and the standardized mortality ratios in the first week/month/year of widowhood were calculated based on person-year calculations.

Results. The annualized suicide rates in widowed persons were highest in the first week after bereavement: 941 males and 207 females per 100000 . The corresponding standardized mortality ratios were approximately 34 and 19 respectively. In the first month(s) after bereavement, the rates and the ratios decreased, first rapidly, then gradually. Except in older widows, they did not reach the baseline levels during the first year after bereavement.

Conclusions. The suicide risk of widowed persons is increased in the days, weeks and months after bereavement. Widowed persons are a clear-cut risk group under the aegis of undertakers, priests and general practitioners.

Received 29 May 2007; Revised 5 December 2007; Accepted 14 December 2007; First published online 29 January 2008

Key words: Bereavement, suicide, time effects.

\section{Introduction}

Suicide rates are elevated after stressful life events such as the loss of a partner, or separation. Bereavement is a typical example of such stressful events and is responsible for the high suicide rates of the widowed (Kreitman, 1988). This work aimed to examine the effect of time on suicide rates immediately after bereavement, that is within 1 week, 1 month and 1 year. The results were expected to suggest conclusions regarding necessities and opportunities in the prevention of suicide.

\section{Method}

The suicide data were extracted from the Swiss cause of death statistics (Minder \& Zingg, 1989), courtesy of the Federal Statistical Office in Neuchatel. The data entered in the analyses cover the period 1987-2005. ICD-8 coding was in use until 1994, and ICD-10 coding after that. Since 1998, an extra code (X618) reveals assisted suicides, thus enabling this cause of death to be differentiated in the subsequent analyses. Assisted suicides that were recorded since 1998 were excluded from the

* Address for correspondence: Dr V. Ajdacic-Gross, University Psychiatric Hospital Zurich, Research Unit for Clinical and Social Psychiatry, Militärstrasse 8, Postfach 1930, CH 8021, Zürich, Switzerland.

(Email: vajdacic@dgsp.uzh.ch) analysis. Like other violent deaths, suicides figured regularly as the main cause of death. Population data were derived from the 1990 and 2000 censuses.

The time between bereavement and subsequent death, specifically suicide, was determined by linkage of individual records. This linkage was enabled by merging two data streams from the death records: the records of deceased married persons comprising the date of birth of the partner, and the records of deceased widowed persons comprising the date of death of the partner. This information has been available since 1987. Additional matching criteria were gender and location of habitation (canton).

The analyses were restricted to deaths of married persons for the period 1987-2004 in order to retain the 12-month follow-up period in all widowed persons. We included only couples in the analyses that we could match regarding all criteria. Probable suicidepact couples (identified by marital status, same day of suicide, and same method of suicide) were excluded. Probable homicide-suicides were identified in a similar way (identified by marital status, suicide within 10 days after homicide).

The suicide mortality of the widowed was calculated specifically for the first 12 months and, applying the person-years approach (Rothman \& Greenland, 1998), for the first month and the first week after bereavement. Apart from sex we differentiated the data by age ( $<60$ years versus $\geqslant 60$ years). 


\section{Results}

During the period 1987-2005 there were 26841 suicides registered in the Swiss mortality statistics. Thirty-nine suicides were identified as probable homicide-suicides, all but one being committed by men; $35(90 \%)$ of these were carried out using firearms. Eight pairs of suicides that were probably due to suicide pacts were reclassified. Thirteen assisted suicides that occurred within 12 months of bereavement were also excluded from the analyses. Three hundred and sixty-six suicides of widowed persons could be related unequivocally to a partner who had died within the previous 12 months, whereas 44 suicides of widowed persons that seemingly fullfilled the 12month criterion could not be matched unequivocally.

About one out of 600 widowers (2500 widows) committed suicide in the first year of widowhood. The annualized suicide rate was highest in the first week after bereavement: 941 men and 207 women per 100000. The corresponding standardized mortality ratios (SMRs) were approximately 34 and 19. The overall SMR in the first week after bereavement (22, see 'all' in Table 1) is only slightly higher than the SMR of the women; this is attributed to the fact that most widowed persons are women, and women generally have distinctly lower suicide rates than men. After the first week, the rates and the ratios decreased much more rapidly than after the first month after bereavement.

The separation of data by sex and age $(<60$ years versus $\geqslant 60$ years) showed interesting differences even though some of the figures are fairly small. The SMRs of young and middle-aged women are at least as high as the SMRs of men. By contrast, the SMRs of older women are distinctly lower than in men and they smooth down immediately after the first week after bereavement.

\section{Conclusions}

This study attempts to provide, for the first time, an insight into the time-related dynamics of suicide immediately after bereavement. It is well recognized that bereavement is a stressful life event that increases the risk of various causes of death (Kaprio et al. 1987), and in particular of suicide (Erlangsen et al. 2004; Agerbo, 2005). It has also been shown that the time effect is crucial; the risk of suicide in widows and widowers decreases after the first year of widowhood (Erlangsen et al. 2004) until it is similar to the overall rate (MacMahon \& Pugh, 1965). Thus, analyses on a more general level, such as on suicides by marital status, are often flawed with regard to the suicide risk of widowed persons. Hence, it is not surprising that analyses that take no account of the time after bereavement in longitudinal modelling (Kposowa, 2000) may fail to find noteworthy associations between widowhood and suicide.

The person-year calculations in this study indicate that the suicide rate is dramatically high in the initial period after bereavement. The SMR for suicide was about 20-30 in the first week after bereavement. This dramatic increase in the SMR clearly surpasses the odds ratio for the onset of major depression immediately after bereavement, which is of the order of 15 (Zisook \& Kendler, 2007). The analyses have also confirmed findings from earlier studies that the suicide rates in young widowed persons are distinctly higher than in older widowed persons (Kreitman, 1988; Smith et al. 1988; Luoma \& Pearson, 2002; Yip \& Thorburn, 2004). The finding that suicide after bereavement is more frequent in men than in women (Li, 1995) requires some clarification. It applies only to older widows and widowers, whereas younger widows have a suicide risk that is similar to, or even higher than, widowers within the same age group.

We assume that many suicides immediately after bereavement, that is within the first week of the death of the partner, represent what we might call 'rash act' suicides $\uparrow$. Furthermore, we assume that such suicides are similar to many other suicides occurring immediately after stressful life events, for example after the loss of a partner or a close friend, or after significant quarrels, major disappointments, or bad news. There have been different approaches to categorize such suicides. Some authors differentiate between planned and unplanned suicides (Conner, 2004), whereas a different perspective arises in connection with impulsive suicides. It is noteworthy that one out of four nearly lethal suicide attempts is an impulsive attempt (Simon et al. 2001). 'Rash act' suicides deserve closer investigation regarding prevention opportunities. These might differ from measures set up to prevent suicides after several weeks or months of grief.

It has been suggested that widows and widowers are a group suitable for preventive efforts (Luoma \& Pearson, 2002), especially as they have contact with undertakers, priests and often also general practitioners after bereavement. The first days after bereavement provide a preliminary time 'window' to intervene and establish support for persons at risk of suicide. For many of them, such an intervention might have beneficial effects in assisting them in coping with

$\uparrow$ Suicide as a 'rash act' is a reminiscence on Victor Bailey's book on suicide in a Victorian city (Bailey, 1998). However, in the first place this term is a proxy for immediate or reflex reactions. 'Unplanned suicide' is a more general term and does not include the time-related effects typical for this kind of suicide. 
Table 1. Suicide rates and standardized mortality ratios (SMRs) 1 year, 1 month and 1 week after bereavement; Switzerland, 1987-2005, by gender

\begin{tabular}{|c|c|c|c|c|c|c|}
\hline Gender (and age) & $\begin{array}{l}\text { Widowed } \\
\text { persons } \\
\text { 1987-2004 }\end{array}$ & Time after bereavement & $\begin{array}{l}\text { Matched } \\
\text { suicides } \\
\text { 1987-2005 }\end{array}$ & $\begin{array}{l}\text { Suicide rate } \\
\text { (per } 100000 \\
\text { person-years) }\end{array}$ & SMR & $\begin{array}{l}\text { Confidence } \\
\text { interval }\end{array}$ \\
\hline \multirow[t]{4}{*}{ All } & \multirow[t]{4}{*}{453200} & 1st week & 36 & 413.1 & 21.7 & $15.2-30.2$ \\
\hline & & 1st month (excluding 1st week) & 30 & 81.0 & 4.2 & $2.9-6.0$ \\
\hline & & 1st year (excluding 1st month) & 300 & 72.2 & 3.5 & $3.1-3.9$ \\
\hline & & 1st year & 366 & 80.8 & 4.3 & $3.8-4.7$ \\
\hline \multirow[t]{4}{*}{ All, 20-59 years } & \multirow[t]{4}{*}{30116} & 1st week & 11 & 1899.3 & 87.0 & $48.2-157.2$ \\
\hline & & 1st month (excluding 1st week) & 4 & 162.5 & 7.3 & $2.7-19.5$ \\
\hline & & 1st year (excluding 1st month) & 34 & 123.2 & 5.2 & $3.7-7.2$ \\
\hline & & 1st year & 49 & 162.7 & 7.5 & $5.6-9.9$ \\
\hline \multirow[t]{4}{*}{ All, $\geqslant 60$ years } & \multirow[t]{4}{*}{423084} & 1st week & 25 & 307.3 & 9.7 & $6.5-14.3$ \\
\hline & & 1st month (excluding 1st week) & 26 & 75.2 & 2.3 & $1.6-3.4$ \\
\hline & & 1st year (excluding 1st month) & 266 & 68.6 & 2.0 & $1.8-2.2$ \\
\hline & & 1st year & 317 & 74.9 & 2.4 & $2.1-2.6$ \\
\hline \multirow[t]{4}{*}{ Men } & \multirow[t]{4}{*}{127135} & 1st week & 23 & 940.7 & 34.4 & $22.9-51.7$ \\
\hline & & 1st month (excluding 1st week) & 21 & 202.1 & 7.2 & $4.7-11.1$ \\
\hline & & 1st year (excluding 1st month) & 180 & 154.5 & 5.2 & $4.5-6.0$ \\
\hline & & 1st year & 224 & 176.2 & 6.4 & $5.7-7.3$ \\
\hline \multirow[t]{4}{*}{ Men, 20-59 years } & \multirow[t]{4}{*}{11398} & 1st week & 6 & 2737.3 & 86.9 & $39.0-193.4$ \\
\hline & & 1st month (excluding 1st week) & 1 & 107.3 & 3.3 & $0.5-23.7$ \\
\hline & & 1st year (excluding 1st month) & 14 & 134.0 & 3.9 & $2.3-6.6$ \\
\hline & & 1st year & 21 & 184.2 & 5.8 & $3.8-9.0$ \\
\hline \multirow[t]{4}{*}{ Men, $\geqslant 60$ years } & \multirow[t]{4}{*}{115737} & 1st week & 17 & 763.8 & 15.4 & $9.5-24.7$ \\
\hline & & 1st month (excluding 1st week) & 20 & 211.4 & 4.2 & $2.7-6.5$ \\
\hline & & 1st year (excluding 1st month) & 166 & 156.5 & 2.9 & $2.5-3.4$ \\
\hline & & 1st year & 203 & 175.4 & 3.5 & $3.1-4.0$ \\
\hline \multirow[t]{4}{*}{ Women } & \multirow[t]{4}{*}{326065} & 1st week & 13 & 207.3 & 19.4 & $11.2-33.3$ \\
\hline & & 1st month (excluding 1st week) & 9 & 33.8 & 3.1 & $1.6-5.9$ \\
\hline & & 1st year (excluding 1st month) & 120 & 40.1 & 3.4 & $2.9-4.1$ \\
\hline & & 1st year & 142 & 43.5 & 4.1 & $3.4-4.8$ \\
\hline \multirow[t]{4}{*}{ Women, $20-59$ years } & \multirow[t]{4}{*}{18718} & 1st week & 5 & 1389.0 & 119.0 & $49.5-286.0$ \\
\hline & & 1st month (excluding 1st week) & 3 & 196.1 & 16.5 & $5.3-51.1$ \\
\hline & & 1st year (excluding 1st month) & 20 & 116.6 & 9.2 & $5.9-14.2$ \\
\hline & & 1st year & 28 & 149.6 & 13.3 & $9.2-19.3$ \\
\hline \multirow[t]{4}{*}{ Women, $\geqslant 60$ years } & \multirow[t]{4}{*}{307347} & 1st week & 8 & 135.4 & 4.3 & $2.1-8.5$ \\
\hline & & 1st month (excluding 1st week) & 6 & 23.9 & 0.7 & $0.3-1.7$ \\
\hline & & 1st year (excluding 1st month) & 100 & 35.5 & 1.0 & $0.8-1.2$ \\
\hline & & 1st year & 114 & 37.1 & 1.2 & $1.0-1.4$ \\
\hline
\end{tabular}

Baseline suicide rates within the same period: all, 18.9 ; all $20-59$ years, 21.8 ; all $\geqslant 60$ years, 31.7 ; men, 27.4; men 20-59 years, 31.5 ; men $\geqslant 60$ years, 49.8 ; women, 10.7 ; women $20-59$ years, 11.7 ; women $\geqslant 60$ years, 39.7 .

any subsequent stressful life events and crises. Prevention projects are needed that address the occupational groups involved and help them to identify and support bereaved persons at risk for suicide.

\section{Limitations}

This study is subject to several limitations. First, suicide counts underestimate the actual number of suicide deaths to some extent. This is probably true even for Switzerland, despite its well-developed health system, which includes comprehensive forensic medicine. Moreover, the records of the cause of death include only incomplete information about psychiatric morbidity, but no information on previous suicide attempts. The second limitation relates to incomplete information regarding widowhood and divorce: for example, the length of marriage before widowhood, 
first-time widowhood or repeated, the number and ages of children, and whether the suicidee was cohabiting with a new partner. In addition, the analysis of linked data of married partners showed that the overall data overestimate the rates of widowed men due to specific suicide types (homicide suicides, suicide pacts). Analysis of suicide records in Basel (Frei et al. 2006) has suggested that the number of homicide suicides and suicide pacts is probably greater than that detected by the procedure used in this analysis. Perhaps this is associated with another limitation: there is doubtless a sizeable proportion of cases that could not be linked due to errors in input data.

\section{Acknowledgements}

Suicide data were extracted from Swiss mortality records with kind permission of the Swiss Federal Statistical Office in Neuchatel.

\section{Declaration of Interest}

None.

\section{References}

Agerbo E (2005). Midlife suicide risk, partner's psychiatric illness, spouse and child bereavement by suicide or other modes of death: a gender-specific study. Journal of Epidemiology and Community Health 59, 407-412.

Bailey V (1998). 'This Rash Act': Suicide Across the Life Cycle in the Victorian City. Stanford University Press: Stanford, CA, 349 pp.

Conner KR (2004). A call for research on planned vs. unplanned suicidal behavior. Suicide and Life-Threatening Behavior 34, 89-98.

Erlangsen A, Jeune B, Bille-Brahe U, Vaupel JW (2004). Loss of partner and suicide risks among oldest old: a population-based register study. Age and Ageing 33, 378-383.

Frei A, Han A, Weiss MG, Dittmann V, Ajdacic-Gross V (2006). Use of army weapons and private firearms for suicide and homicide in the region of Basel, Switzerland. Crisis 27, 140-146.

Kaprio J, Koskenvuo M, Rita H (1987). Mortality after bereavement: a prospective study of 95,647 widowed persons. American Journal of Public Health 77, 283-287.

Kposowa AJ (2000). Marital status and suicide in the National Longitudinal Mortality Study. Journal of Epidemiology and Community Health 54, 254-261.

Kreitman N (1988). Suicide, age and marital status. Psychological Medicine 18, 121-128.

Li G (1995). The interaction effect of bereavement and sex on the risk of suicide in the elderly: an historical cohort study. Social Science and Medicine 40, 825-828.

Luoma JB, Pearson JL (2002). Suicide and marital status in the United States, 1991-1996: is widowhood a risk factor? American Journal of Public Health 92, 1518-1522.

MacMahon B, Pugh TF (1965). Suicide and the widowed. American Journal of Epidemiology 81, 23-31.

Minder CE, Zingg W (1989). The mortality statistics of Switzerland. Data quality of causes of death and of professional codes. Report No. 155 (Amtliche Statistik der Schweiz). Swiss Federal Statistical Office.

Rothman KJ, Greenland S (1998). Modern Epidemiology, 2nd edn. Lippincott: Philadelphia.

Simon TR, Swann AC, Powell KE, Potter LB, Kresnow MJ, O'Caroll PW (2001). Characteristics of impulsive suicide attempts and attempters. Suicide and Life-Threatening Behavior 32, 49-59.

Smith JC, Mercy JA, Conn JM (1988). Marital status and the risk of suicide. American Journal of Public Health 78, 78-80.

Yip PSF, Thorburn J (2004). Marital status and the risk of suicide: experience from England and Wales, 1982-1996. Psychological Reports 94, 401-407.

Zisook S, Kendler KS (2007). Is bereavement-related depression different than non-bereavement-related depression? Psychological Medicine 37, 779-794. 